\title{
Primary source and selection of corn (maize)
}

\author{
Rikhsivoy Tellyaev ${ }^{1, *}$, Kobuljan Azizov ${ }^{2}$, and Ilhom Mamatkulov ${ }^{1}$ \\ ${ }^{1}$ Tashkent State Agrarian University, Universitetskaya str., 2, 100140, Tashkent, Uzbekistan \\ ${ }^{2}$ Scientific Experimental Station of Maize Breeding and Seed Production (SESMBSP), Zangi-ota \\ district, Tashkent, Uzbekistan.
}

\begin{abstract}
In desert conditions, corn is one of the most promising crops due to its resistance to salinity, drought, heat, adverse environmental conditions, high productivity and versatility. Conducting field experiments, sowing, phonological observations, biometric measurements, plant care, yield determination new varieties of agricultural crops were performed. Samples were also evaluated on the length of the paniculo. In particular, it was $44.7 \mathrm{~cm}$ in the control $\mathrm{K}-521$, followed by $40.8 \mathrm{~cm}$ in K-431, $49.9 \mathrm{~cm}$ in $\mathrm{K}-581$ and $55.4 \mathrm{~cm}$ in K-538, whereas in the technical variants, it was $55.4 \mathrm{~cm}$ in K-538, $50 \mathrm{~cm}$ at K-368, and even it was $65 \mathrm{~cm}$ in K-494. Of the 57 samples studied, only 8 , № 9, 15, 17, 26, 27, 31, 42, 46 samples were found suitable for future selection work. Valuable aspects of these samples were that flowering period was 75-108 days, milk-ripening period was 87-108 days, and full ripening period was 118-130 days. These indicators were 76 days of germination, 79 days of flowering, 91 days of milk ripening and 127 days of full ripening in the "Orange-160" maize. It was found that the repining period of "Orange" maize was 9 days earlier than the control varieties, 9,15 and 17.
\end{abstract}

\section{Introduction}

Corn (Maize) is the fifth most common cereal crop in world agriculture, and is grown on about 50 million hectares of land in 85 countries [1-3]. The main producers of corn are India (6.2-18.2 million hectares), Nigeria (2.1-6.9 million hectares), Sudan (1.5-7.1 million hectares), the United States (1.9-6.5 million ha). Due to water shortages in 80 countries around the world, 7 million people die every year. The problem of food security is growing due to the loss of agricultural land per hectare and global climate change. In order to meet the needs of the population in food, industrial raw materials and livestock feed by increasing the volume of production using irrigated lands in the world, it is necessary to systematically improve the technology of cultivation, taking into account the morphobiological properties of field crops, soil and climate, water supply [6-7, 11-12 ]. In desert conditions, corn is one of the most promising crops due to its resistance to salinity, drought, heat, adverse environmental conditions, high productivity and versatility. In arid regions, the creation of new varieties, hybrids for additional grain, green fodder, fodder, the

\footnotetext{
${ }^{*}$ Corresponding author: rixsivoy.tillayev@yandex.com
} 
organization and implementation of primary seed production is one of the pressing issues in agriculture.

The creation of stunted (deaf) corn varieties harvested with a combine is of great importance for the national economy. In the United States, 96 percent of the total corn crop area is allocated for the creation of this variety and hybrids [7-8]. In various selection programs abroad, they have successfully used the methods of selection, inter-variety and inter-line hybridization, and in the creation of the starting material - intsuxt, mutagenesis, backcross and other methods. Moraru [2, 10-11] created a new starting material for Sorghumaryzoidum (yellow) glass-grain forage maize using the backcross method in Moldavian conditions. This method was the first to create tiny sterile lines and fertility restorers. Fertility-based cross-breeding and mutagenesis in the selection of maize along the Volga, and on the basis, drought and frost-resistant Pishchevoe 614, Perspektivnyy 1, Jubilee 20, Pishchevoe 35, Volgar 1, Volgar 2 hybrid maize varieties were created [9-11, 13].

It is known that water weed is characterized by the intensity of the initial growth and the emergence of grass after mowing. It was observed that 45-50 tons/ha of green mass from twice mowing was produced, followed by 9-11 tons/ha of hay and seed yield up to 2 tons per hectare [9-11]. The greatest achievements have been made in the selection of grain oats in the laboratory. Based on criteria such as yield and seed quality, simultaneous ripening of sown grain, and resistance to diseases and pests, B.N. Malinovskiy, A.P. Pospelov, M.P. Jukova, E.K. Vakhopsky isolated hundreds of specimens. Throug using the method of selfpollination and selection, a number of varieties were created that exceeded the standards in terms of key characteristics that were valuable to the farm $[1-5,10]$

Scientific research on the selection of corn for irrigated lands has also been conducted in the Central Asian republics [14]. In the 50-90s of the XX century, scientists of Uzbekistan S.K. Kadamov, V.T. Korolenko, S.A. Mazurin, Z.S. Vinogradov, X.R. Muminov, M.A. Ernazarov, G.A. Ayrapetov, P.P.Oleynik and I.V. Massino conducted extensive research in field of maize variety [10]. "Four-month", "six-month", Rich-Miaze", "Katta-bosh", "Khoraki" maize varieties were created, and have been preserved till now. However, the varieties of sugar corn created at that time were not widely introduced due to their late ripening, low yield and quality indicators, as well as the lack of seed production and incomplete cultivation technology. Variety samples, which serve as the primary valuable source of sugar corn in the republic, have not been studied in comparison with local and foreign species in the collection nursery, their morpho-biology, phenology have not been studied in depth and are not divided into groups by ripening period. There was no mixing of selected varieties, samples, creation of new target grain, hybrids and varieties of sugar corn, and insufficient attention was paid to the selection process of corn and the collection of primary sources. Through using the inter-species hybridization and then selection method of the local Food Oats variety with broom maize. The Giant Uzbekistan variety at the Uzbek Livestock Scientific Research Institute, which plants were up to 6 meters tall [23].

In addition, Uzbek maize variety grown for grain and silage through using the methods of interspecific hybridization was created [1,3]. This hybrid was created by hybridizing 160 varieties of local bare-grained "Short late" and "Orange", and selecting the form of high-yielding sugar beet, in 1980. Ecologically and geographically distant varieties of this plant were used in the creation of 5-grain varieties of fast-growing Uzbekistan. In the hybridization, the Higher deaf variety of $S$. bantuorum from the World Collection of Botanical Research Institute was used as the mother form, and the native Six-month-old ( $S$. cernuum $H$.) Variety was used as the parent form [7-9]. In the second-seventh generation, a fast-ripening hybrid population was isolated from the hybrid offspring, which was distinguished by the height of the plants and the high grain yield relative to the mother 
form. In fact, the number of scientific research was done, in which different disease resistant and productive varieties of maize were created in past years. However, there has been no research on hybrids and hybridization of maize in recent years. Therefore, this research was aimed at performing comparison of more than 300 domestic and foreign varieties, samples and hybrids of sugar corn in accordance with the selection methods, selection of the best varieties, hybrids with valuable indicators of traditional selection $[10,13]$.

\section{Materials and methods}

Field and production experiments were conducted in 2007-2017 in the experimental field of the Scientific Experimental Station of Maize Breeding and Seed Production (SESMBSP) of Zangiota district, Tashkent region.

\subsection{Soil conditions}

The experimental field was typical of gray, the mechanical composition of which consists of heavy sandy soil. The agrochemical condition of the experimental field soil showed that $30 \mathrm{~cm}$ of the tillage layer was moderately supplied with gross nutrient reserves, such as humus $1.20 \%$, nitrogen $0.1 \%$, phosphorus $0.160 \%$ and potassium $1.60 \%$. The moisture content of field soil was $22 \%$, groundwater was located at a depth of $13-15 \mathrm{~m}$. The amount of mobile forms of phosphorus, potassium and nitrates in the $0-30 \mathrm{~cm}$ layer was as follows: $\mathrm{P}_{2} \mathrm{O}_{5}-35.5 \mathrm{mg} / \mathrm{kg}, \mathrm{K}_{2} \mathrm{O}-290 \mathrm{mg} / \mathrm{kg}, \mathrm{N}_{2} \mathrm{O}_{3}-28.2 \mathrm{mg} / \mathrm{kg}$, and in the $30-50 \mathrm{~cm}$ layer, it was $\mathrm{P}_{2} \mathrm{O}_{5}-32 \mathrm{mg} / \mathrm{kg}, \mathrm{K}_{2} \mathrm{O}-180 \mathrm{mg} / \mathrm{kg}, \mathrm{N}_{2} \mathrm{O}_{3}-8.25 \mathrm{mg} / \mathrm{kg}$, respectively.

\subsection{Climatic conditions}

The duration of periods when the air temperature was above $0{ }^{\circ} \mathrm{C}$ is on average 330 days, the vegetation period for thermophilic plants was 214 days (above $10^{\circ} \mathrm{C}$ ). Summers are hot and atmospheric without precipitation. In the hottest Month-July, the average monthly temperature is $28-29^{\circ} \mathrm{C}$, and the richness of thermal resources, abundance of heat and light means that it is possible to grow a variety of heat-loving plants in artificially irrigated conditions of the Tashkent region. Conducting field experiments, sowing, phonological observations, biometric measurements, plant care, yield determination new varieties of agricultural crops were performed. Statistical analysis of the resulted was done by using B.A. Dospekhov.

An experimental research Standard technological map "On the care and cultivation of agricultural crops" was created [5-8]. Agro-technical measures carried out in the experimental field were carried out in the recommended time for the cultivation of corn varieties. The experimental area was plowed to a depth of 30-35 cm. Prior to plowing, a total of $90 \mathrm{~kg}$ of recommended phosphorus and $60 \mathrm{~kg}$ of potassium fertilizers were applied. When the soil was plowed in the spring, it was stormed to a depth of $12-15 \mathrm{~cm}$ with a toothed harrow, and the mulch was suppressed. Bulldozers and planting troughs were taken with a tractor for irrigation. Manual planting was carried out in the collection, control, competition seedlings to obtain the specified seedling thicknesses [12]. When the plant was fully germinated, it was worked between the rows, the field work was done alone, cultivated with a tractor, weeded by hand against weeds and watered 5 times. The first feeding was carried out during the period of 5-6 leaf emergence of plants, and the second during the emergence of 10-12 leaves per $100 \mathrm{~kg}$ of nitrogen fertilizer on the affected substance [12-13]. 
300 primary source varieties of sugar corn from foreign and domestic plants Genetic Bank, scientific research organizations were collected in the nursery for in-depth study of biological properties, morphological features, selection of cultivars with valuable economic characteristics, control seedlings and primary seed production processes, including 195 varieties from the Plant Research Institute, 78 from IKBA, 6 from South Korea, 4 from the Livestock and Poultry Research Institute, and 17 from the Maize Breeding and Seed Research Experimental Station. The results of the study were compared with the standard varieties, resistant to drought, heat and cold, salinity, pests and diseases, high grain and green mass yield, high sugar content of stem juice, grouped by ripening periods. In the collection nursery conducted in 2007-2014, hybrids and cultivars of sugar beet were divided into three groups according to the length of the growing season, their stem height, number of leaves, stalk length, first leaf stalk spacing, wet and dry mass yield and sugar content of stalk juice.

\section{Results and discussion}

According to the data obtained, the plant height was $234.3 \mathrm{~cm}$ during the ripening of grain milk. In samples 5, 7, 13, 14, 16, 17, 29, 30, 35, 36, 39, 41, 44, 46, 54, 55, 69, 70, 72, 77, 78 and 81 , the plant height was $3-52 \mathrm{~cm}$. On the length of paniculo, it was also determined that the indicators of samples were different, as well as not subject to one legislation. Samples were also evaluated on the length of the paniculo. In particular, it was $44.7 \mathrm{~cm}$ in the control K-521, followed by $40.8 \mathrm{~cm}$ in K-431, $49.9 \mathrm{~cm}$ in K-581 and 55.4 $\mathrm{cm}$ in K-538, whereas in the technical variants, it was $55.4 \mathrm{~cm}$ in K-538, $50 \mathrm{~cm}$ at K-368, and even it was $65 \mathrm{~cm}$ in K-494. The shortest length of paniculo was observed in the samples $6,9,18,26,33,34,52,54,57,58,69,70,80$. Of the 85 samples studied, only 8 pieces, that was $2,38,55,61,63,79,84,85$ finite samples were evaluated as fit for future selection studies (Table 1). Valuable aspects of these samples were manifested in the following: flowering period 56-80 days, milk ripening period 69 - 102 days, full ripening 86 - 115 days. These indicators, fasting in 5 varieties of template Uzbekistan accounted for 66 days, flowering 70, milk ripening 87, full ripening 107 days, and the selected samples were determined that the ripening period compared to the template variety was homogeneous.

The results of the experiment on the leaf amount showed that the number of leaves in Uzbekistan-5 variety was amounted to 10 grains, however, the highest leaf number in the "Rich maize" and "K-200" was observed, accounted for 15-16 grains. The multiplicity of the number of leaves according to the laws of selection is one of the signs of procreation. However, the number of leaves in the soil-climatic conditions of Uzbekistan is important in increasing the yield of photosynthesis and heat resistance, as well as leaf yield. In order to create varieties for the future cultivation of green fodder, samples with the number of 16 , 34 and 37 were selected, which has average 18-19 leaves. In the fast-growing group of maize, green and dry mass of Uzbekistan-5 were 34.49 tons/ha and 10.59 tons/ha, respectively. 
Table 1. Biometric indicators of plants of the fast-growing sugar maize in the collection seedlings (milk ripening period, average 2007-2014 years).

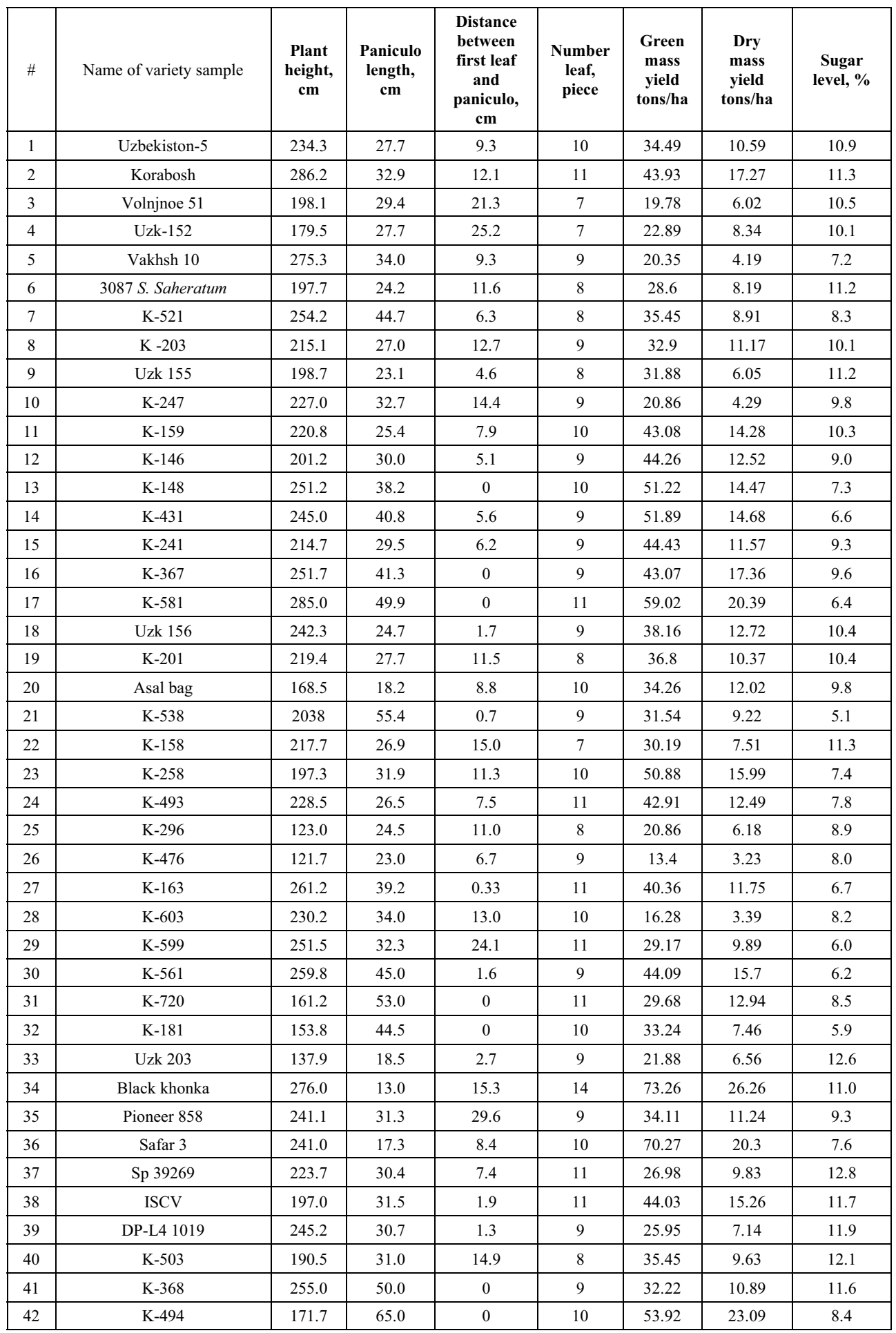




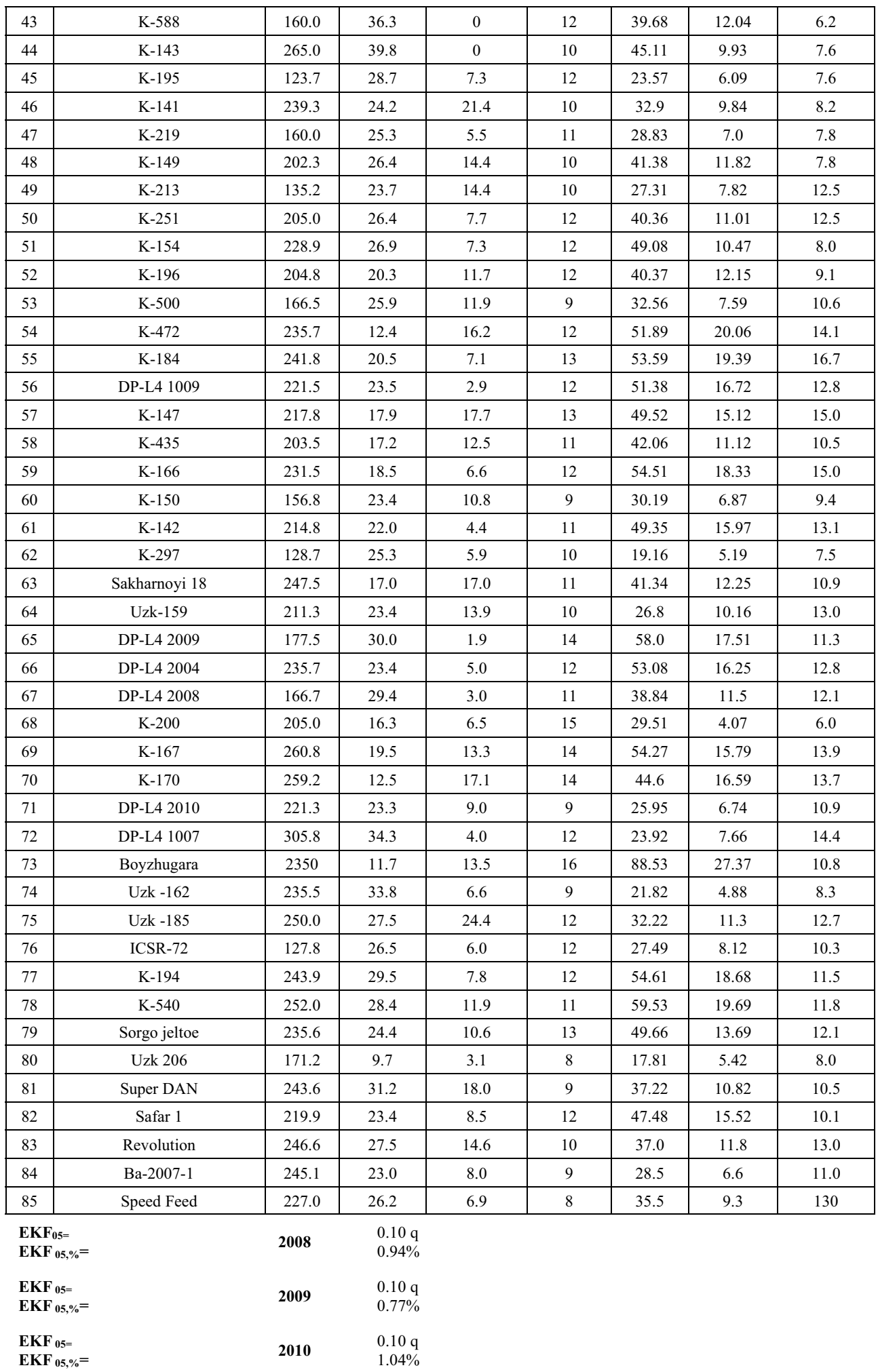


During the milk ripening period, the plant height of K-213, K-502, K-175 varieties was low, that was, $104.0-168.3 \mathrm{~cm}$, and in other varieties it was more than $200 \mathrm{~cm}$. The highest vegetation rates were observed in "Orange" variety, accounted for $160-278.8 \mathrm{~cm}$, followed by "Uzbekistan-18" with $318.9 \mathrm{~cm}$ and "Karabash" $-286.2 \mathrm{~cm}$.

According to the pertinent results, "Orange" variety's height was taken as minimum in the experiment, therefore, the following varieties were disposed: K-293, K-347, K-587, Pishchevoy, DP-L4 1002, Uzk-545, K-293, K-157, K-210, K-298. There was no strict pattern in the morphobiology of sample of each variety, especially in paniculo length, distance from the first leaf to the underside of the paniculo, and number of leaves. However, there was positive and negative change in green and dry mass. The highest amount of green and dry mass among the samples of medium-ripe sugar corn varieties in the collection nursery was determined. Accordingly, K-600 was took $1^{\text {st }}$ place with 101.75 tons/ha green mass and 32.35 tons/ha dry mass, followed by "RAOBAIF" with 64.81 tons/ha and 25.88 tons/ha at $2^{\text {nd }}$ place, and "Tashkent belozernoe" with 91.64 tons/ha and 27.76 tons/ha at $3^{\text {rd }}$ place. During the experiment, the leading samples in sugar content were identified, and relatively high, 16-17.6 \% sugar were observed in the samples, 3,6,8,27,32 and 38 (Table 1)

Of the 57 samples studied, only 8, 9, 15, 17, 26, 27, 31, 42, 46 samples were found suitable for future selection work. Valuable aspects of these samples were that flowering period was 75-108 days, milk-ripening period was 87-108 days, and full ripening period was 118-130 days. These indicators were 76 days of germination, 79 days of flowering, 91 days of milk ripening and 127 days of full ripening in the "Orange-160" maize. It was found that the repining period of "Orange" maize was 9 days earlier than control varieties, 9,15 and 17. The number of leaves was observed as the same in almost all maize varieties. The law of sharp increase in sugar content in comparison with fast-ripening varieties was determined. An increase in the sugar content from $16.8 \%$ to $17.6 \%$ was observed in six samples, such as 2,7,9,10,11 and 12 (Table 2).

Table 2. Biometric indicators of plants of the fast-growing sugar maize in the collection seedlings (milk ripening period, average 2007-2014 years).

\begin{tabular}{|c|c|c|c|c|c|c|c|c|}
\hline \# & $\begin{array}{c}\text { Name of variety } \\
\text { sample }\end{array}$ & $\begin{array}{c}\text { Plant } \\
\text { height, cm }\end{array}$ & $\begin{array}{c}\text { Paniculo } \\
\text { length, cm }\end{array}$ & $\begin{array}{l}\text { Distance } \\
\text { between } \\
\text { first leaf } \\
\text { and } \\
\text { paniculo, } \\
\text { cm } \\
\end{array}$ & $\begin{array}{l}\text { Number } \\
\text { leaf, piece }\end{array}$ & $\begin{array}{c}\text { Green } \\
\text { mass } \\
\text { yield } \\
\text { tons/ha }\end{array}$ & $\begin{array}{c}\text { Dry mass } \\
\text { yield } \\
\text { tons/ha }\end{array}$ & $\begin{array}{c}\text { Sugar } \\
\text { level, } \\
\%\end{array}$ \\
\hline 1 & $\begin{array}{c}\text { Orange } 160 \\
\text { (control) }\end{array}$ & 278.8 & 23.9 & 12.3 & 13 & 61.93 & 18.22 & 16.7 \\
\hline 3 & K-504 & 236.7 & 15.7 & 11.3 & 10 & 36.63 & 11.87 & 16.0 \\
\hline 4 & K-550 & 107.3 & 29.0 & 1.7 & 8 & 22.05 & 6.44 & 14.6 \\
\hline 5 & K-587 & 88.3 & 25.7 & 0 & 9 & 27.81 & 9.26 & 11.2 \\
\hline 6 & Pishevoy & 143.0 & 28.0 & 8.9 & 5 & 20.35 & 5.09 & 16.0 \\
\hline 7 & K-144 & 247.7 & 22.7 & 15.1 & 12 & 55.96 & 12.42 & 13.6 \\
\hline 12 & K-161 & 251.7 & 15.0 & 10.3 & 17 & 49.69 & 14.4 & 8.5 \\
\hline 13 & K-598 & 209.5 & 35.4 & 12.6 & 10 & 31.88 & 11.13 & 7.2 \\
\hline 14 & K-293 & 95.8 & 27.7 & 6.2 & 12 & 18.32 & 4.4 & 9.5 \\
\hline 15 & K-601 & 249.2 & 12.9 & 12.2 & 14 & 66.99 & 19.89 & 12.3 \\
\hline 16 & K-347 & 91.5 & 23.9 & 15.0 & 9 & 23.40 & 5.68 & 11.0 \\
\hline 17 & K-528 & 250.0 & 23.4 & 4.1 & 13 & 62.75 & 23.96 & 15.0 \\
\hline 18 & K-248 & 178.4 & 35.2 & 20.0 & 10 & 37.65 & 11.1 & 8.7 \\
\hline 19 & K-502 & 168.3 & 18.5 & 7.9 & 11 & 27.31 & 9.28 & 11.3 \\
\hline 20 & K-157 & 99.2 & 22.5 & 7.7 & 13 & 17.64 & 4.11 & 7.2 \\
\hline 21 & K-190 & 146.4 & 21.0 & 4.1 & 11 & 31.38 & 12.09 & 9.2 \\
\hline
\end{tabular}




\begin{tabular}{|c|c|c|c|c|c|c|c|c|}
\hline 22 & K-475 & 135.7 & 24.4 & 10.4 & 13 & 29.00 & 7.93 & 10.7 \\
\hline 23 & K-210 & 106.2 & 26.7 & 7.7 & 11 & 27.14 & 8.26 & 10.8 \\
\hline 24 & DP-L4 1005 & 244.2 & 26.2 & 9.6 & 13 & 26.80 & 9.5 & 15.5 \\
\hline 25 & K-298 & 95.7 & 21.5 & 2.3 & 12 & 20.35 & 7.56 & 14.2 \\
\hline 26 & RAOBAIF & 316.7 & 21.5 & 3.2 & 17 & 64.81 & 25.88 & 13.7 \\
\hline 27 & K-544 & 270.0 & 29.0 & 13.1 & 12 & 46.13 & 20.67 & 17.4 \\
\hline 28 & DP-L4 2005 & 201.2 & 25.5 & 2.8 & 9 & 26.46 & 6.59 & 7.2 \\
\hline 29 & $\begin{array}{c}\text { Tashkent } \\
\text { belozernoe }\end{array}$ & 273.3 & 14.2 & 8.8 & 18 & 91.64 & 27.76 & 11.1 \\
\hline 30 & Yantar ranny & 231.9 & 24.7 & 12.1 & 11 & 52.33 & 15.4 & 11.3 \\
\hline 31 & K-288 & 119.8 & 20.7 & 9.6 & 13 & 46.98 & 16.18 & 11.5 \\
\hline 32 & K-569 & 253.3 & 25.7 & 0 & 12 & 62.75 & 21.9 & 18.4 \\
\hline 33 & Daulet & 217.5 & 21.4 & 9.0 & 16 & 53.42 & 14.42 & 11.2 \\
\hline 34 & K-600 & 283.3 & 19.9 & 8.5 & 17 & 101.75 & 32.35 & 11.1 \\
\hline 35 & DP-L4 2015 & 278.0 & 30.9 & 12.3 & 12 & 44.09 & 13.41 & 13.2 \\
\hline 36 & $\mathrm{~K}-211$ & 120.6 & 23.0 & 12.6 & 9 & 19.33 & 6.72 & 12.8 \\
\hline 37 & $\mathrm{~K}-236$ & 195.7 & 22.4 & 6.6 & 12 & 40.02 & 14.23 & 15.1 \\
\hline 38 & $\mathrm{~K}-372$ & 227.5 & 20.0 & 7.9 & 13 & 50.71 & 16.66 & 17.4 \\
\hline 39 & K-392 & 241.8 & 13.0 & 17.9 & 15 & 45.62 & 18.8 & 13.0 \\
\hline 40 & Sp 39105 & 167.0 & 17.4 & 1.3 & 7 & 14.6 & 3.29 & 4.2 \\
\hline 41 & Speed Feed & 225.5 & 27.7 & 10.8 & 11 & 30.51 & 11.44 & 12.3 \\
\hline 42 & Uzk-213 & 102.3 & 20.0 & 0.9 & 15 & 42.05 & 20.57 & 17.6 \\
\hline 43 & Uzbekistan short & 144.6 & 19.4 & 7.9 & 18 & 66.33 & 17.77 & 8.6 \\
\hline 44 & Safar 2 & 250.3 & 21.7 & 11.4 & 12 & 54.13 & 17.79 & 10.7 \\
\hline 45 & $\mathrm{~K}-417$ & 276.2 & 19.2 & 6.2 & 16 & 57.66 & 24.76 & 15.0 \\
\hline 46 & Sugar Grase & 212.0 & 24.7 & 8.8 & 13 & 52.12 & 16.11 & 14.0 \\
\hline 47 & $\mathrm{~K}-175$ & 103.5 & 27.7 & 5.9 & 13 & 41.72 & 12.28 & 10.5 \\
\hline 48 & ICSSH 28 & 280.0 & 22.8 & 4.7 & 14 & 60.7 & 20.7 & 16.8 \\
\hline 49 & ICSV 112 & 153.1 & 22.5 & 3.3 & 12 & 34.7 & 12.7 & 13.0 \\
\hline 50 & ICSSH 58 & 254.0 & 22.8 & 6.5 & 14 & 54.5 & 19.2 & 15.9 \\
\hline 51 & S-35 & 213.5 & 20.0 & 4.2 & 14 & 56.4 & 17.9 & 15.9 \\
\hline 52 & ICSR 174 & 145.1 & 24.3 & 3.0 & 13 & 43.0 & 12.9 & 14.1 \\
\hline 53 & ICSV 25275 & 241.0 & 13.4 & 8.0 & 13 & 54.4 & 19.5 & 17.6 \\
\hline 54 & GulDU & 136.2 & 19.8 & 8.5 & 15 & 41.5 & 13.5 & 15.2 \\
\hline 55 & ICSR 93046 & 276.1 & 17.5 & 5.9 & 16 & 57.4 & 21.5 & 16.1 \\
\hline 56 & ICSV 25280 & 233.8 & 12.3 & 6.2 & 12 & 36.0 & 12.1 & 17.1 \\
\hline 57 & ICSV25279 & 246.6 & 14.0 & 8.9 & 13 & 44.1 & 14.9 & 16.2 \\
\hline & $\begin{array}{c}\text { EKF05= } \\
\text { EKF05,\% }=\end{array}$ & $\begin{array}{l}0.14 \mathrm{q} \\
1.5 \%\end{array}$ & & & & & & \\
\hline
\end{tabular}

Biometric indicators of 46 samples of sugar beet belonging to the late ripening group, hybrid samples belonging to the late ripening group in the collection nursery were evaluated in depth in 2007-2014.Biometric parameters of all samples were studied according to the growth phases of sugar beet (Table 3). "Uzbekistan 18" maize was taken as the control for the experiment, which height was $318.9 \mathrm{~cm}$. However, only "D-L4 1015" maize was $359.3 \mathrm{~cm}$, whereas the rest of sample varieties was lower than the control one. The length of paniculo was the same in Samples 5, 7, 17, 18, 19, 22, 23, 29, 40, 45, and 46 as "Uzbekistan 18", control maize variety. The number of leaves in the control was 17 , and it was 18 and 19 in "DP-L4 2003" and DP-L4 2018", respectively. The green mass yield was one of the main indicators in the experiment, which was 94.08 tons/ha in the control, whereas the highest yield was found in "DP-L4 2003" and "DP-L4 1016", accounted for 133.63 tons/ha and 130.58 tons/ha, correspondingly.

The sugar content of plant sap in "Uzbekistan 18 " was $17.4 \%$, and it was $17.6 \%$ in sample 19 , followed by sample 21 with $18.8 \%$ and sample 33 with $17.8 \%$. The period from germination to paniculo process was very short, 60 days in the samples of the Botanical Research Institute $(3,4,5,6,7,8,9,10,11,12,13,14,15)$, and it was 70 days in samples, $3,4,6,12$ and 15. It was observed that the duration of this period before flowering was much closer to the "Uzbekistan 18", and the period was shortened. This can be explained by an increase in temperature, and the active passage of the period from paniculo process to flowering. However, this complex process was observed to be accelerated, and the difference between the control and samples during the milk-ripening period was observed to be almost equal. During the full ripening period, the difference between them was on 
average 136-137 days. According to the high level of sugar content of 46 samples in the studied late group (No. - 3, 4, 6, 8, 10, 13, 14, 18, 19, 20, 21, 27, 29, 33, 35, 36, 38, 39, 41 , $42,43,44,45)$, the green mass yield of some samples was $20.0-50.0$ tons less than "Uzbekistan 18".

Table 3. Biometric indicators of plants of the fast-growing sugar maize in the collection seedlings (milk ripening period, average 2007-2014 years)

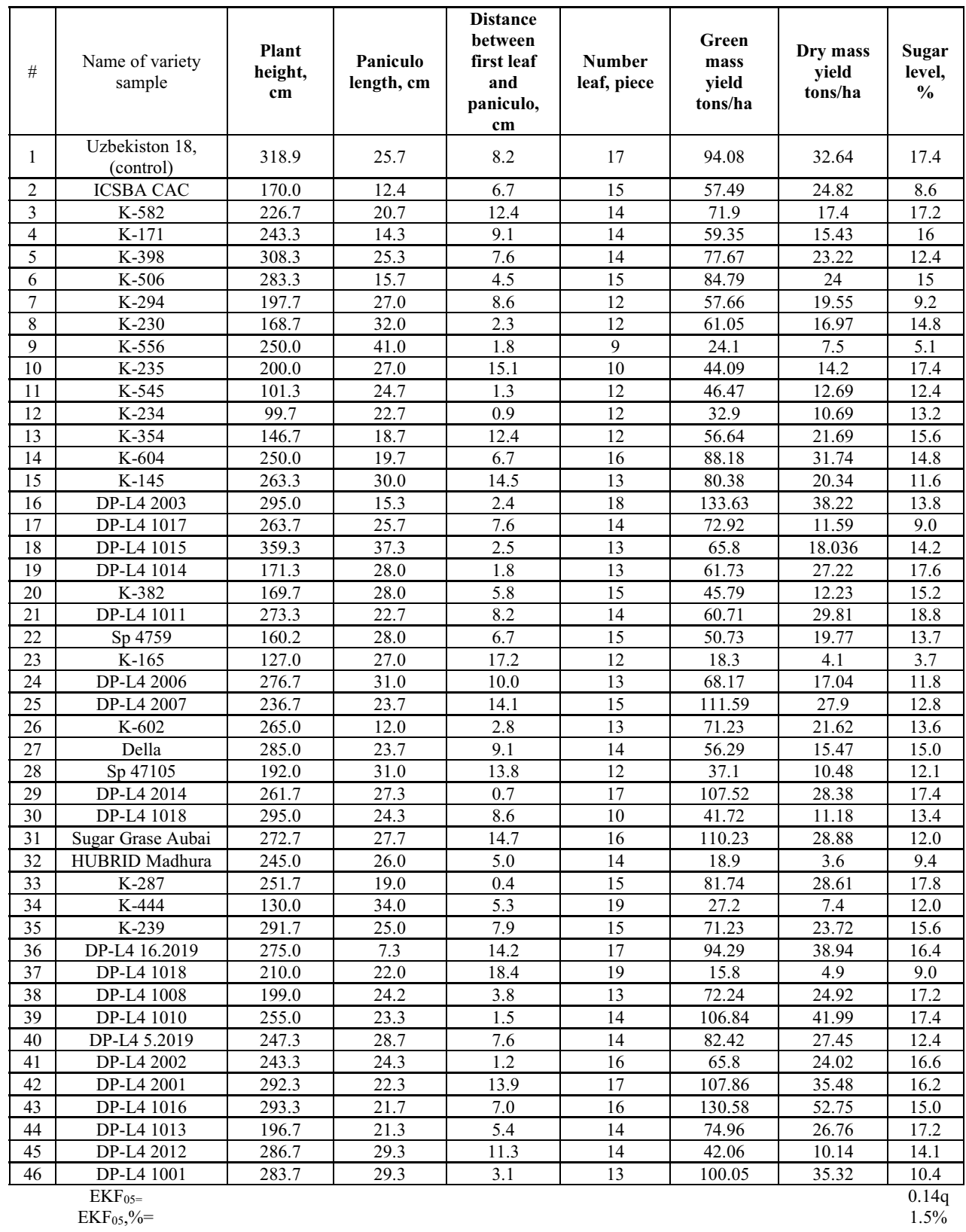




\section{Conclusions}

The number of leaves in the soil-climatic conditions of Uzbekistan is important in increasing the yield of photosynthesis and heat resistance, as well as leaf yield. In order to create varieties for the future cultivation of green fodder, samples with the number of 16 , 34 and 37 were selected, which has average 18-19 leaves. In the fast-growing group of maize, green and dry mass of Uzbekistan-5 were 34.49 tons/ha and 10.59 tons/ha, respectively.

During the milk ripening period, the plant height of K-213, K-502, K-175 varieties was low, that was, $104.0-168.3 \mathrm{~cm}$, and in other varieties it was more than $200 \mathrm{~cm}$. The highest vegetation rates were observed in "Orange" variety, accounted for $160-278.8 \mathrm{~cm}$, followed by "Uzbekistan-18" with $318.9 \mathrm{~cm}$ and "Karabash" with $286.2 \mathrm{~cm}$. The highest amount of green and dry mass among the samples of medium-ripe sugar corn varieties in the collection nursery was determined. Accordingly, K-600 was took $1^{\text {st }}$ place with 101.75 t/ha green mass and 32.35 tons/ha dry mass, followed by "RAOBAIF" with 64.81 tons/ha and 25.88 tons/ha at $2^{\text {nd }}$ place, and "Tashkent belozernoe" with 91.64 tons/ha and 27.76 tons/ha at the third place.

The sugar content of plant sap in "Uzbekistan 18 " was $17.4 \%$, and it was $17.6 \%$ in sample 19 , followed by sample 21 with $18.8 \%$ and sample 33 with $17.8 \%$. The period from germination to paniculo process was very short, 60 days in the samples of the Botanical Research Institute $(3,4,5,6,7,8,9,10,11,12,13,14,15)$, and it was 70 days in samples, $3,4,6,12$ and 15 .

\section{References}

1. S. Rani, P. Schreinemachers, B. Kuziyev, (2018). Cogent Food \& Agriculture, 4, 1 (2018)

2. J. Mammadov, R. Buyyarapu, S. Guttikonda, K. Parliament, I. Abdurakhmonov, S. Kumpatla, Frontiers in plant science, 9 (2018)

3. Y. Peng, F. Li, N. Xu, R. Kulmatov, K. Gao, G. Wang, Y. Zhang, Y. Qiao, Y. Li, H. Yang, S. Hao, Q. Li, S. Khasanov, Chinese Journal of Eco-Agriculture, 29(2), 312-324 (2021)

4. F. Zhong, D. Jiang, Q. Zhao, A. Guo, A. Ullah, X. Yang, X. Ding, Journal of Cleaner Production, 268 (2020)

5. N. Israilovich, K. Meylikovich, A. Shodievich, K. Bozarovich, European science review, 3 (2019)

6. N. Teshaev, B. Mamadaliyev, A. Ibragimov, S. Khasanov, InterCarto. InterGIS, 26(3), 324-333 (2020)

7. A. Jumanov, S. Khasanov, A. Tabayev, G. Goziev, U. Uzbekov, E. Malikov, In IOP Conference Series: Earth and Environmental Science, 614(1), 012150 (2020)

8. D. Wang, Y. Mo, G. Li, C. Wilkerson, G. Hoogenboom, Agricultural Water Management, 251 (2021)

9. Y. Lin, D. Watts, J. Kloepper, H. Torbert, Communications in Soil Science and Plant Analysis. 49, 10 (2018)

10. S. Isaev, S. Khasanov, Y. Ashirov, T. Karabaeva, A. Gofirov, In E3S Web of Conferences, 244, 02012 (2021)

11. S. Isaev, S. Khasanov, Y. Ashirov, A. Gofirov, T. Karabaeva, In E3S Web of Conferences, 244, 02047 (2021) 
12. R. Kulmatov, A. Taylakov, S. Khasanov, Environmental Science and Pollution Research, 28(10), 12245-12255 (2021)

13. O. Abelmasov, L. Ilchenko, Plant varieties studying and protection, 141 (2018)

14. V. Sotchenko, A. Gorbacheva, I. Vetoshkina, N. Orlyanskij, N. Orlyanskaya, O. Panfilova, G. Krivosheev, Maize and Sorghum, 24 (2017)

15. I. Aslanov, S. Khasanov, Y. Khudaybergenov, M. Groll, Ch. Opp, F. Li, E. Ramirez Del-Valle, In E3S Web of Conferences, 227, 02005 (2021)

16. V. Nechaev, P. Mikhailushkin, Y. Davydova, IOP Conference Series: Earth and Environmental Science. 604, 1 (2020)

17. N. Fadhli, M. Farid, R. Effendi, M. Azrai, M. Anshori, Biodiversitas Journal of Biological Diversity, 21, 8 (2020). 